\title{
Aa. Vv., La tragédie à l'époque d'Henri III. Deuxième Série. Vol. 4: 1584-1585
}

\section{Michele Mastroianni}

\section{(2) OpenEdition}

1 Journals

\section{Edizione digitale}

URL: http://journals.openedition.org/studifrancesi/27482

DOI: 10.4000/studifrancesi.27482

ISSN: 2421-5856

\section{Editore}

Rosenberg \& Sellier

\section{Edizione cartacea}

Data di pubblicazione: 31 décembre 2006

Paginazione: 594-595

ISSN: 0039-2944

\section{Notizia bibliografica digitale}

Michele Mastroianni, «Aa. Vv., La tragédie à l'époque d'Henri III. Deuxième Série. Vol. 4: 1584-1585 », Studi Francesi [Online], 150 (L | III) | 2006, online dal 30 novembre 2015, consultato il 08 novembre 2020. URL : http://journals.openedition.org/studifrancesi/27482 ; DOI : https://doi.org/10.4000/ studifrancesi.27482

Questo documento è stato generato automaticamente il 8 novembre 2020.

\section{(c) $(1)$}

Studi Francesi è distribuita con Licenza Creative Commons Attribuzione - Non commerciale - Non opere derivate 4.0 Internazionale. 


\title{
Aa. Vv., La tragédie à l'époque d'Henri III. Deuxième Série. Vol. 4: 1584-1585
}

\author{
Michele Mastroianni
}

\section{NOTIZIA}

La tragédie à l'époque d'Henri III. Deuxième Série. Vol. 4: 1584-1585, «Théâtre français de la Renaissance», fondé par Enea BALMAS et Michel DASSONVILLE, dirigé par Nerina CLERICI BALMAS, Marcel TETEL et Luigia ZILLI, Florence-Paris, Olschki-P.U.F., 2005, pp. 459.

Continua con un ulteriore volume (siamo ormai a quota tredici) la monumentale e benemerita impresa avviata dai compianti E. Balmas e M. Dassonville, che ora animano, infaticabili, N. Clerici Balmas, M. Tetel e L. Zilli. Il corpus tragico dell'epoca di Henri III si arricchisce di tre pièces di grande estensione (la più lunga supera i 5500 versi), due di Jean-Edouard Du Monin e una di Pierre Matthieu. Più che di opere teatrali vere $\mathrm{e}$ proprie, data la loro lunghezza, si tratta di poemi drammatici (anche se rappresentazioni - di collegio, ad esempio - sono attestate): per quanto l'incertezza dello statuto di genere drammatico sia ancora grande, come grande è l'influsso sia della tragedia umanistica di scuola sia della moralité di tradizione medievale.

Gilles Banderier ha curato l'edizione delle due tragedie di Du Monin. La prima, La Peste de la Peste (1584: 2943 versi), fu pubblicata come seconda parte di un ampia raccolta allegorico-morale, Le Quaresme, ed è molto più vicina alla moralité medievale che alla tragedia: il grande interesse di questo testo, mai più edito dopo il 1584, è nell'essere opera di confine fra il genere tragico e il poema religioso-filosofico secondo il modello di Du Bartas, autore che influenzerà anche il testo di Matthieu.

3 La seconda tragedia di Du Monin, qui presentata, L'Orbecc-Oronte (1585: 3094 versi), fu anch'essa pubblicata come parte di una più vasta silloge di poesia morale, Le Phoenix. Come genere è sicuramente più legata della precedente alla tradizione della tragedia senechiana, attraverso la mediazione di Giraldi Cinzio, di cui viene attestata la fortuna francese. Sebbene Du Monin denunci come fonte gli Ecatommiti, un'esame attento della 
pièce evidenzia la dipendenza non tanto dalla novella, quanto dalla tragedia di Giraldi Cinzio sullo stesso soggetto, l'Orbecche appunto. Per certo, l'Orbecc-Oronte è uno dei migliori esempi di quella tragedia fondata sull'orrore e sulla violenza, di gusto senechiano, ma che a Seneca tenta di sostituire modelli 'moderni' per rinnovare il genere, anche contestando l'autorità degli antichi.

Mariangela Miotti ha editato e commentato con una ricca introduzione l'Esther di Pierre Matthieu (1585: 5569 versi). L'argomento è un tema biblico che, da Rivaudeau a Racine, ha lunga e ricca fortuna nella storia della tragédie sainte francese. Nel caso di Matthieu, è anzitutto l'estensione della pièce (nel 1589 l'autore stesso si impegnerà nella ristrutturazione dell'Esther, riorganizzando il testo in due tragedie Vasthi e Aman) a farne un'opera nuova e originale che - come indica il lungo sottotitolo (Histoire tragique en laquelle est representée la condition des Rois et Princes sur le theatre de fortune, la prudence de leur Conseil, les desastres qui surviennent par l'orgueil, l'ambition, l'envie et trahison, combien est odieuse la desobeissance des femmes, finablement comme les Roynes doibvent amollir le couroux des Rois endurciz, sur l'oppression de leurs subjects) - costeggia vari generi, dall'histoire tragique, appunto, all'exemplum morale alla predicazione, addirittura, e infine, come è stato documentato dagli interventi di Louis Lobbes in particolare, alla Sepmaine di Du Bartas, attingendo ampiamente alla poesia alla moda, da Ronsard a Garnier, con un'operazione continua di intertestualità. 